\title{
Dampak Aspek Capital, Assets, Earning, dan Liquidity Pada Kesehatan Keuangan Perbankan
}

\author{
Marliza Noor Hayatie ${ }^{1)}$; Widiya Astuti Alam Sur ${ }^{2)}$; \\ Muhammad Shapiq Gautama ${ }^{3)}$ \\ ${ }^{1-3)}$ Politeknik Negeri Tanah Laut, email : marliza@politala.ac.id.
}

\section{ARTICLES INFORMATION}

\section{ABSTRACT}

\section{JURNAL SEKURITAS \\ (Saham, Ekonomi, Keuangan dan Investasi ) \\ Vol.4, No.1, September 2020 Halaman : $1-14$ \\ (C) LPPM \& Prodi Manajemen UNVERSITAS PAMULANG \\ ISSN (online) : 2581-2777 ISSN (print) : : 2581-2696}

\section{Keyword : \\ Rasio Keuangan; Laporan Keuangan; Return On Assets; Perbankan}

JEL. classification :

C33, G21, G24, N15, N25

\section{Contact Author : \\ PRODI MANAJEMEN UNPAM \\ JL.Surya Kencana No.1 \\ Pamulang Tangerang Selatan - Banten \\ Telp. (021) 7412566, Fax (021) 7412491 Email : \\ sekuritas@unpam.ac.id}

Perbankan memiliki pengaruh yang besar terhadap perekonomian dalam perannya di sebuah negara, sehingga bank dijadikan gambaran kemajuan sebuah negara. Rasio yang digunakan untuk menilai kesehatan keuangan perbankan pada penelitian ini adalah CAEL (Capital, Assets, Earning, Liquidity). Salah satu indikator yang dipakai untuk mengukur tingkat kesehatan keuangan suatu bank adalah Return On Assets (ROA). Data kuantitatif dalam penelitian ini adalah data laporan keuangan pada perusahaan perbankan yang terdaftar di Bursa Efek Indonesia (BEI) periode 2016-2018. Dari penelitian yang dilakukan dapat disimpulkan bahwa rasio BOPO (Biaya Operasional/ Pendapatan Operasional) dari aspek pendapatan, lebih dominan pengaruhnya terhadap Return On Assets (ROA) jika dibandingkan dengan rasio CAR (Capital Adequacy Ratio) dari aspek permodalan, Rasio NPL (Non Performing Loan) dari aspek harta, Rasio LDR (Loan to Deposit Ratio) untuk aspek likuiditas.

Banking has a big interest in planning, in its role in the country; therefore, the bank makes it the country's progress. The ratio used for banking restructuring assessment in this study was CAEL (Capital, Assets, Income, Liquidity). One indicator used to measure the soundness of a bank was Return on Assets (ROA). Quantitative data in this study was the data on financial statements of banking companies submitted on the Indonesia Stock Exchange (IDX) for the period 2016-2018. From the research conducted, it can be concluded that the ratio of BOPO (Operational Costs / Operating Income) from the Budget aspect is a more dominant influence on Return On Assets (ROA) when compared to the CAR (Capital Adequacy Ratio) ratio from the aspect of capital, NPL Ratio (NonPerforming Loan) )) from the aspect of assets, and the LDR (Loan to Deposit Ratio) ratio for the liquidity aspect. 


\section{A. PENDAHULUAN}

Seiring perkembangan zaman saat ini maka peluang dan ancaman semakin banyak, dimana semakin terbukanya peluang usaha yang dihadapkan pada ancaman yang begitu kompleks seperti adanya krisis keuangan. Indikasi munculnya krisis keuangan dapat dilihat dengan adanya perekonomian yang tidak stabil dan juga adanya fluktuasi (Karunia, 2013).

Kinerja keuangan perusahaan dapat digunakan investor untuk mengetahui keadaan perusahaan dan kemudian dapat dipakai untuk mengambil keputusan investasi pada perusahaan tersebut. Media yang digunakan untuk mendapatkan informasi segala kegiatan perusahaan adalah laporan keuangan. Laporan keuangan didapatkan dengan berjalannya system akuntansi dalam sebuah perusahaan (Harahap, 2011). Dalam UU No. 10/1998 perbankan merupakan lembaga yang mengumpulkan simpanan dari rakyat dalam bentuk uang dan kemudian memberikan pinjaman kepada rakyat untuk melakukan kegiatan bisnis dengan memakai uang yang terkumpul dari masyarakat itu sendiri (Rindjin, 2008).

Melalui laporan keuangan sebuah manajemen perbankan dapat memiliki dasar untuk menilai kesehatan keuangannya. Dimana laba bersih dari suatu bank dapat terlihat dalam laporan keuangan. Semakin tinggi laba yang didapatkan oleh sebuah perbankan melalui operasionalnya, maka semakin baik tingkat kinerja keuangan perbankan tersebut. Indikator laba dari sebuah perbankan dapat dihitung dengan memakai rasio ROA. ROA dipakai agar dapat mengukur tingkat pencapaian sebuah entitas perbankan untuk mendapatkan laba. ROA merupakan perhitungan rasio dengan membandingkan keuntungan bersih dengan seluruh total yang ada pada perusahaan. Jika nilai ROA tinggi maka tinggi juga laba yang didapatkan oleh sebuah perusahaan perbankan, begitu juga sebaliknya. Dan dengan itu, para pemegang saham dapat menikmati keuntungan dari investasi yang ditanamkan. (Setiawan, 2015).

Di industry perbankan, evaluasi kinerja yang memadai didapatkan dengan melihat kinerja keuangan. Pemerintah harus lebih memperhatikan sektor perbankan sehingga perbankan mendapatkan kepercayaan lagi dari masyarakat dan pelaku bisnis. Untuk mengetahui tingkat kesehatan sebuah bank, diperlukan beberapa analisis rasio dari berbagai aspek. Aspek yang dipakai untuk mengukur kinerja perbankan secara umum adalah Capital, Assets, Management, Earning, dan Liquidity (CAMEL). Namun, management tidak bisa dipakai untuk mengukur kinerja keuangan secara kuantitatif, karena penilaiannya melalui kepatuhan bank terhadap aturan. Salah satunya, management diukur melalui proksi Batas Minimum Pemberian Kredit (BMPK).

Beberapa rasio yang dipakai untuk melakukan riset ini diantaranya (1) Rasio CAR (Capital Adequacy Ratio) untuk aspek permodalan; (2) Rasio NPL untuk aspek harta; (3) Rasio BO/PO (Biaya Operasional/ Pendapatan Operasional) untuk aspek pendapatan; dan (4) Rasio LDR (Loan to Deposit Ratio) untuk aspek likuiditas.

\section{B. KAJIAN LITERATUR}

\section{Pengertian Bank}

Perbankan memiliki pengaruh yang besar terhadap perekonomian dalam perannya di sebuah negara, sehingga bank dijadikan gambaran kemajuan sebuah negara. Menurut (Rindjin, 2012) Bank adalah sebuah lembaga yang bergerak dibidang pemberian pinjaman ataupun bantuan dalam bentuk lain yang berhubungan dengan peredaran uang. Jika peranan bank dalam suatu negara semakin besar, maka dapat disimpulkan bahwa negara tersebut semakin maju.

Menurut (Kasmir, 2012) Bank adalah sebuah lembaga yang melakukan penghimpunan uang dari rakyat yang kemudian uang tersebut dipinjamkan kepada 
rakyat lain yang membutuhkan modal untuk membangun ataupun memperbesar usahanya.

Perbankan didefinisikan sebagai sesuatu yang berhubungan dengan Bank, baik cara, proses, kegiatan maupun kelembagaannya (Darmawi, 2011).

Jadi dapat disimpulkan, pengertian bank adalah sebagai kegiatan mengumpulkan uang, kemudian mendistribusikan uang tersebut, dan juga menyediakan bantuanbantuan lain. Aktivitas mengumpulkan dan mendistribusikan dana adalah usaha pokok sebuah lembaga keuangan, selain itu ada juga aktivitas pendukungnya yaitu menyediakan jasa-jasa bank lainnya.

2. Laporan Keuangan

Sumber informasi keuangan pada sebuah entitas perbankan adalah laporan keuangan. Laporan keuangan memiliki manfaat yang sangat besar dalam pengambilan keputusan dalam suatu perusahaan, para pemagang saham, serta para calon investor sebagai pertimbangan untuk mengambil keputusan.

(Fahmi, 2012) menyatakan bahwa laporan Keuangan merupakan gambaran tentang aktivitas keuangan dalam sebuah perusahaan, dimana informasi tersebut sangat berguna bagi manajemen untuk mengetahui efektivitas dan efisiensi keuangan perusahaan tersebut.

Menurut (Alexandri, 2008) salah satu informasi yang biasa digunakan agar dapat memprediksi keadaan sebuah entitas adalah laporan keuangan.

Menurut (Sutrisno, 2012) laporan keuangan adalah kesimpulan dari kegiatan pencatatan keuangan yang telah disusun agar bisa tersaji bagi pihak yang membutuhkan informasi keuangan tersebut sehingga dapat mengambil keputusan dengan tepat.

Dari beberapa definisi laporan keuangan yang sudah dibahas diatas, kesimpulan yang dapat diambil adalah bahwa pada umumnya laporan keuangan dapat menggambarkan pencapaian aktivitas keuangan dalam sebuah entitas pada periode tertentu.

3. Return On Assets

Adalah perhitungan rasio untuk memperlihatkan hasil bagi antara laba bersih terhadap keseluruhan harta bank adalah ROA. Rasio ini memperlihatkan kemampuan bank dalam mengelola asset yang dimiliki. ROA adalah rasio yang memperlihatkan tingkat efisiensi sebuah perusahaan perbankan untuk mendapatkan keuntungan dengan memberdayakan harta yang dimilikinya (Pandia, 2012). Jika nilai ROA tinggi maka laba yang didapatkan oleh sebuah entitas perbankan juga tinggi. Berikut adalah rumus ROA:

$$
\mathrm{ROA}=\frac{\text { Laba Sebelum Pajak }}{\text { Total Aset }} \times 100 \%
$$

4. Capital (Permodalan)

Modal merupakan faktor utama dalam dunia bisnis, begitu juga bagi perusahaan perbankan. Akan tetapi, harta bank hanya sebagian kecil saja yang di danai oleh modal. Menurut (Pandia, 2012) Modal bank terbagi menjadi 2 (dua), yaitu modal utama dan modal tambahan. Modal utama yaitu modal yang di dapatkan dari saham istimewa serta surat berharga. Simpanan masyarakat bukan merupakan modal bagi sebuah bank, meskipun hampir seluruh harta yang dimiliki oleh bank berasal dari dana yang disimpan masyarakat.

Sesuai peraturan pemerintah tentang permodalan minimum perbankan terkait Basel III yang ditetapkan pada peraturan OJK Nomor 11/POJK.03/2016 bahwa CAR (Capital Adequacy Ratio) minimal harus 8\%. Jadi, jika CAR sebuah bank adalah $8 \%$, ini berarti bahwa bank itu harus serius melakukan perbaikan dalam menjalankan 
aktivitasnya. Karena jika bank tersebut tidak serius dalam melakukan perbaikan dalam menjalankan aktivitasnya maka akan dilakukan penutupan operasional oleh Bank Indonesia.

Rasio CAR yang digunakan untuk mengukur variabel capital diperoleh dengan perhitungan membandingkan antara modal utama dengan ATMR (Harmono, 2011), yang dirumuskan sbb:

$$
\mathrm{CAR}=\frac{\text { Modal }}{\text { Aktiva Tertimbang Menurut Risiko }(\text { ATMR })} \times 100 \%
$$

\section{Asset (Aset)}

Upaya yang dilakukan untuk mengetahui kualitas dari harta yang dimiliki bank adalah dengan melakukan penilaian terhadap semua harta. Penilaian asset selalu disesuaikan dengan peraturan yang dikeluarkan oleh pemerintah. Yaitu melakukan perbandingan diantara jenis harta produktif tertentu terhadap total harta produktif. Setelah itu, mengklasifikasikan rasio cadangan penghapusan harta produktif terhadap aktiva produktif (Kasmir, 2011).

Menurut Bank Indonesia Non performing Loan (NPL) sangat erat hubungannya dalam menentukan tingkat kesehatan kualitas asset. NPL memperlihatkan seberapa besar kemungkinan kredit bermasalah di sebuah bank karena kredit macet nasabah. Rasio NPL dipakai untuk megetahui kinerja variabel assets dengan melakukan perhitungan perbandingan antara kualitas produktif bermasalah dibagi dengan aktiva produktif, dengan rumus sbb:

6. Earning (Rentabilitas)

$$
\mathrm{NPL}=\frac{\text { Kualitas produktif bermasalah }}{\text { Aktiva produktif }}
$$

Perlunya penilaian terhadap kemampuan sebuah perusahaan perbankan dalam menghasilkan laba agar perusahaan perbankan tersebut dapat melakukan kegiatan operasional dan investasi. Rentabilitas merupakan pendapatan dari investasi yang dinyatakan dengan persentase dari jumlah modal yang ditanamkan (Veithzal, 2013). Kemampuan bank untuk dapat memaksimalkan keuntungan yang didapatkan dapat diukur dengan aspek earning. Selainitu, aspek ini dipakai untuk mengukur pencapaian bank dari sisi efisiensi dan profitabilitasnya. Bank yang dapat terus meningkatkan rentabilitasnya merupakan bank yang sehat (Kasmir, 2011).

BOPO adalah rasio yang dipakai untuk mengukur variabel earning, agar dapat diketahui perhitungan dari perbandingan biaya operasi terhadap pendapatan operasional bank (Harmono, 2011). Rumus untuk menghitung rasio BOPO aadalah sbb :

$$
\mathrm{BOPO}=\frac{\text { Total beban operasional }}{\text { Total pendapatan operasional }}
$$

7. Liquidity (Likuiditas)

Apabila bank mampu membayar seluruh hutang lancarnya, maka bank itu dapat dianggap sebagai bank yang likuid. Kewajiban lancar disini maksudnya adalah uang yang disimpan oleh masyarakat seperti tabungan, giro dan deposito. Apabila hutang telah jatuh tempo, maka bank dapat segera melakukan pembayaran tepat waktu. Disamping itu juga, bank harus dapat menyalurkan kredit kepada masyarakat yang membuat permohonan kredit (Kasmir, 2011).

Pengukuran nilai likuiditas dapat menggunakan rasio LDR agar mengetahui besarnya jumlah pinjaman yang diserahkan untuk modal usaha masyarakat dan jumlah uang simpanan yang dikumpulkan bank dari masyarakat. Sebagai sumber likuiditasnya, 
bank dapat menunjukkan dengan kemampuan mengembalikan dana yang tesimpan kepada pemilik dana melalui pendapatan dari pinjaman yang didistribusikan ke masyarakat. Jika rasio LDR tinggi maka likuiditas bank menjadi menurun. Ini berarti bank membutuhkan uang yang besar agar bisa memberikan kreditnya kepada masyarakat (Veithzal, 2013).

Menurut (Lely, 2007) Rasio LDR digunakan untuk mengukur variabel liquidity yang dihitung dengan rumus sebagai berikut:

$$
\text { LDR }=\frac{\text { Total Loan }}{\text { Total Deposito }} \times 100 \%
$$

8. Kinerja Keuangan

Penilaian kinerja keuangan dalam sebuah entitas diperlukan agar entitas dapat melihat aktivitas operasionalnya sehingga dapat bersaing dengan perusahaan lain.

Menurut (Fahmi, 2012) Kesuksesan sebuah perusahaan yang tergambar dalam bentuk hasil yang didapatkan setelah melakukan aktivitas perusahaan terlihat dari pencapaian kerja keuangan.

Menurut (Rudianto, 2013) Kinerja keuangan merupakan pencapaian keberhasilan dari manajemen perusahaan dalam memanfaatkan asset perusahaan secara optimal dalam jangka waktu tertentu. Perusahaan sangat membutuhkan laporan kinerja keuangan agar dapat mengukur tingkat kesuksesan perusahaan dengan melihat kegiatan keuangan yang telah dilakukan.

\section{METODOLOGI PENELITIAN}

Berdasarkan sifatnya, penelitian ini merupakan penelitian korelasional, yaitu penelitian yang dilakukan dengan tujuan untuk melihat analisis antara dua gejala atau lebih. Sedangkan berdasarkan tempatnya, penelitian ini merupakan jenis penelitian lapangan (field research). Sementara klasifikasi berdasarkan datanya penelitian ini adalah penelitian kuantitatif. Penelitian kuantitatif adalah penelitian yang penyajian datanya berupa angkaangka dan menggunakan analisa statistik biasanya bertujuan untuk menunjukkan pengaruh antara variabel, menguji teori dan mencari generalisasi yang mempunyai nilai prediksi.

Penelitian ini menggunakan desain korelasi yaitu hubungan antara variabel bebas $X_{1}, X_{2}, X_{3}, X_{4}$ terhadap variabel terikat . Terdapat variabel bebas (independent variable) yaitu CAR (X1), NPL(X2), BOPO (X3), dan LDR (X4) pada rasio keuangan dan ROA (Y) pada kinerja keuangan

Dalam penelitian kuantitatif, analisis data merupakan kegiatan setelah data dari seluruh responden atau sumber data lain terkumpul. Kegiatan dalam analisis data adalah mengelompokkan data berdasarkan variabel dan jenis responden, mentabulasi data berdasarkan variabel dari seluruh responden, menyajikan data tiap variabel yang diteliti, melakukan perhitungan untuk menjawab rumusan masalah dan melakukan perhitungan untuk menguji hipotesis yang telah diajukan.

Teknik Analisis Data pada penelitian ini adalah Analisis Regresi Lineir Berganda yang dikelompokkan menjadi Uji Asumsi Klasik dan Uji Hipotesis. Teknik analisis data dilakukan dengan bantuan SPSS 26.0 for Windows . 


\section{HASIL DAN PEMBAHASAN}

Uji Asumsi Klasik dilakukan sebelum menguji hipotesis penelitian, untuk mengetahui apakah data yang diperoleh memenuhi syarat untuk dilakukan uji hipotesis pada model regresi linier yang akan digunakan.

1. Hasil Uji Multikolineritas

Uji multikolinearitas dilakukan untuk memastikan apakah di dalam sebuah model regresi ada interkorelasi atau kolinearitas antar variabel bebas. Pada penelitian ini kolinearitas antar variabel bebas didasarkan pada koefisien korelasi Pearson dan nilai standar error koefisien beta. Berdasarkan hasil analisis data pada SPSS diperoleh hasil sebagai berikut:

Tabel 1. Hasil Analisis Korelasi Pearson Antar Variabel Bebas

\begin{tabular}{ccc}
\hline Variabel Bebas & $\begin{array}{l}\text { Pearson } \\
\text { Correlation }\end{array}$ & Kriteria \\
\hline $\boldsymbol{X}_{\mathbf{1}}$ dengan $\boldsymbol{X}_{\mathbf{2}}$ & $-0,549$ & Tidak terjadi Kolinearitas \\
$\boldsymbol{X}_{\mathbf{1}}$ dengan $\boldsymbol{X}_{\mathbf{3}}$ & $-0,687$. & Tidak terjadi Kolinearitas \\
$\boldsymbol{X}_{\mathbf{1}}$ dengan $\boldsymbol{X}_{\mathbf{4}}$ & 0,127 & Tidak terjadi Kolinearitas \\
$\boldsymbol{X}_{\mathbf{2}}$ dengan $\boldsymbol{X}_{\mathbf{3}}$ & 0,465 & Tidak terjadi Kolinearitas \\
$\boldsymbol{X}_{\mathbf{2}}$ dengan $\boldsymbol{X}_{\mathbf{4}}$ & $-0,145$ & Tidak terjadi Kolinearitas \\
$\boldsymbol{X}_{\mathbf{3}}$ dengan $\boldsymbol{X}_{\mathbf{4}}$ & $-0,059$ & Tidak terjadi Kolinearitas \\
\hline
\end{tabular}

Sumber: Hasil Olah Data, 2020

Berdasarkan data tabel di atas dapat diketahui bahwa korelasi antara variabel $X_{1}$ dan $X_{2}$ adalah $r_{X_{1} X_{2}}=-0,549$. Korelasi antara variabel $X_{1}$ dan $X_{3}$ adalah $r_{X_{1} X_{3}}=-0,687$. Korelasi antara variabel $X_{1}$ dan $X_{4}$ adalah $r_{X_{1} X_{4}}=0,127$. Korelasi antara variabel $X_{2}$ dan $X_{3}$ adalah $r_{X_{2} X_{3}}=0,465$. Korelasi antara variabel $X_{2}$ dan $X_{4}$ adalah $r_{X_{2} X_{4}}=-0,145$, dan korelasi antara variabel $X_{3}$ dan $X_{4}$ adalah $r_{X_{3} X_{4}}=-0,059$.

Korelasi antar variabel bebas termasuk ke dalam kategori yang lemah yaitu $r<0,8$. Korelasi yang rendah antar variabel bebas menunjukkan bahwa multikolinearitas tidak terdeteksi. Selanjutnya, kolinearitas antar variabel bebas juga dapat dilihat berdasarkan nilai standar error beta. Diperoleh hasil analisis sebagai berikut:

Tabel 2. Hasil Analisis Koefisien Standar Error Beta

\begin{tabular}{cccc}
\hline Variabel Bebas & $\begin{array}{l}\text { Std. } \\
\text { Error }\end{array}$ & Koef.Beta & \multicolumn{1}{l}{ Kriteria } \\
\hline $\boldsymbol{X}_{\mathbf{1}}$ & 0,014 & $-0,017$ & Tidak terjadi Kolinearitas \\
$\boldsymbol{X}_{\mathbf{2}}$ & 0,063 & $-0,084$ & Tidak terjadi Kolinearitas \\
$\boldsymbol{X}_{\mathbf{3}}$ & 0,003 & $-0,100$ & Tidak terjadi Kolinearitas \\
$\boldsymbol{X}_{\mathbf{4}}$ & 0,005 & 0,0002 & Tidak terjadi Kolinearitas \\
\hline
\end{tabular}

Sumber: Hasil Olah Data, 2020

Berdasarkan data tabel di atas dapat diketahui bahwa nilai standar error dari variabel bebas berturut-turut adalah $\varepsilon_{-} 1=0,014, \varepsilon \_2=0,063, \varepsilon \_3=0,003$, dan $\varepsilon_{-} 4=0,005$. sementara nilai koefisien beta variabel bebas adalah $\beta \_1=-0,017, \beta \_2=-0,084, \beta \_3=-$ 0,100 , dan $\beta_{4} 4=0,000$. Nilai standar error dan koefisien beta yang rendah yaitu kurang dari 1 menunjukkan tidak terjadinya multikolinearitas antar variabel bebas.

Oleh karena berdasarkan koefisien korelasi dan standar error beta menunjukkan tidak terjadinya multikolinearitas antar variabel bebas, maka dapat disimpulkan bahwa data yang akan diolah tidak menunjukkan gejala multikolinearitas. 
2. Hasil Uji Autokorelasi

Uji asumsi autokorelasi digunakan untuk mengetahui apakah ada korelasi antar observasi pada periode tertentu dengan observasi sebelumnya terhadap variabel yang diteliti. Oleh karena dalam penelitian ini digunakan data runtun waktu maka perlu diadakan uji asumsi autokorelasi. Model regresi yang baik adalah model regresi yang bebas dari gejala autokorelasi. Dalam penelitian ini dilakukan pengujian dengan Run test menggunakan SPSS. Run test digunakan untuk menguji apakah residual pada variabel penelitian terdapat korelasi yang tinggi atau tidak. Jika antar residual tidak terdapat korelasi maka dapat dikatakan bahwa residual terjadi secara acak yang berarti tidak terdapat auokorelasi pada data penelitian.

Berikut disajikan hasil pengujian residual pada variabel penelitian dengan Run test pada SPSS:

Tabel 3. Hasil Runs Test SPSS

\begin{tabular}{|c|c|}
\hline Model & $\begin{array}{c}\text { Unstandardized } \\
\text { Residual }\end{array}$ \\
\hline Test Value $^{\mathrm{a}}$ &, 01669 \\
\hline Cases $<$ Test Value & 10 \\
\hline Cases $>=$ Test Value & 11 \\
\hline Total Cases & 21 \\
\hline Number of Runs & 12 \\
\hline Asymp. Sig. (2-tailed) & 0,991 \\
\hline
\end{tabular}

Sumber : Hasil Olah Data, 2020

Hasil run test menunjukkan bahwa nilai Asymp. Sig (2-tailed) $=0.991>0.05$ yang berarti data yang dipergunakan dalam penelitian ini cukup random sehingga dapat dikatakan tidak terdapat masalah autokorelasi pada data penelitian yang diuji.

3. Hasil Uji Heteroskedatis

Uji heteroskedastisitas digunkan untuk menguji apakah ada perbedaan varians dari residual pada data yang diteliti. Model regresi yang baik adalah model regresi yang bebas dari gejala heterokedastisitas. Untuk mengetahui ada tidaknya heteroskedastisitas pada data yang diolah peneliti berdasarkan pada gambar Scatter Plot residual variabel dependent dan variabel independen. Berikut hasil analisisnya:

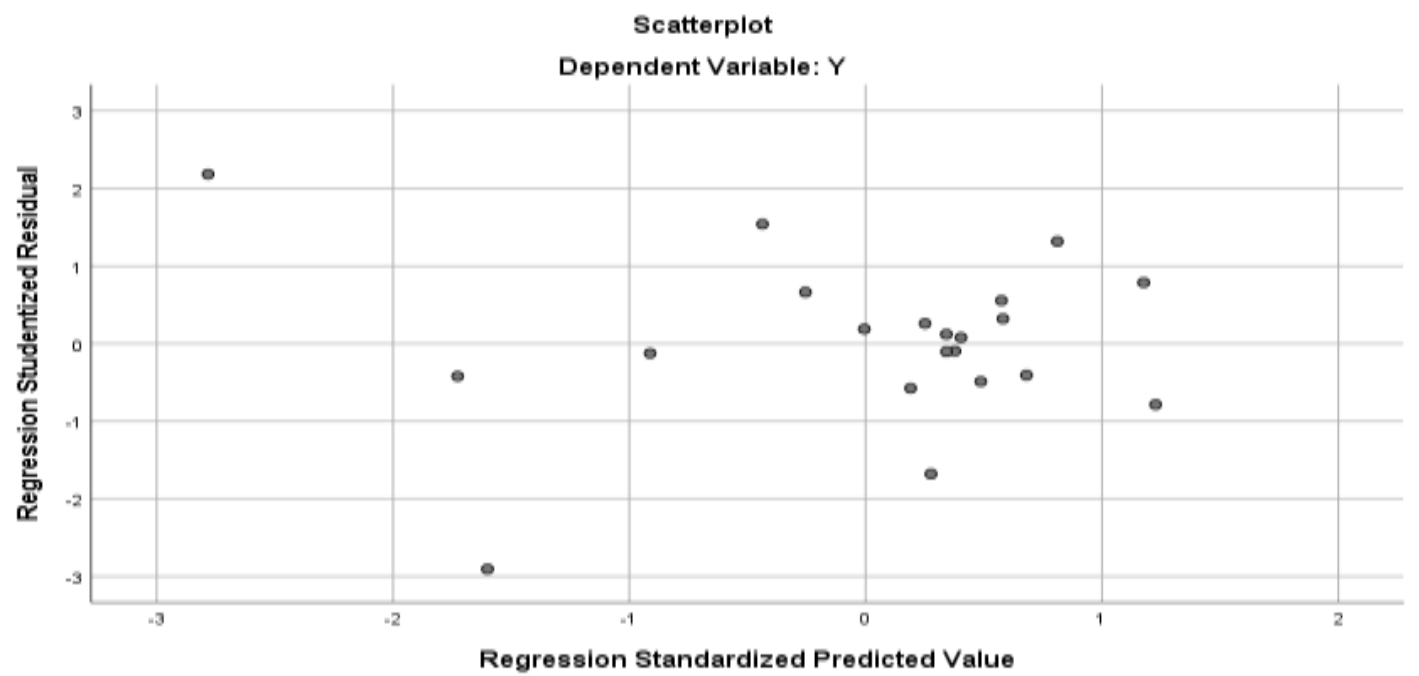

Jurnal SEKURITAS (Saham, Ekonomi, Keuangan dan Investasi ) , Vol.4, No.1, September 2020.... 7 
Gambar 1. Scatter Plot Regresi

Berdasarkan Output Scatter Plot residual regresi di atas, dapat dilihat bahwa titik-titik data menyebar di atas dan di bawah angka 0. Penyebaran titik-titik data juga tidak membentuk pola penyebaran tertentu. Sehingga dapat dikatakan bahwa model regresi yang akan diujikan tidak memiliki gejala heteroskedastisitas.

Selanjutnya, Uji Hetroskedastisitas juga dapat dilihat dari nilai korelasi spearman variabel bebas terhadap residual pengamatan dengan uji 2 sisi sebagai berikut:

Tabel 4. Hasil Analisis Uji Heteroskedatis

\begin{tabular}{ccc}
\hline $\begin{array}{c}\text { Variabel } \\
\text { Bebas }\end{array}$ & $\begin{array}{c}\text { Spearman } \\
\text { Correlation } \\
\text { Sig 2-tailed }\end{array}$ & Kriteria \\
\hline $\boldsymbol{X}_{\mathbf{1}}$ & 0,893 & Tidak terjadi heteroskdastisitas \\
$\boldsymbol{X}_{\mathbf{2}}$ & 0,760 & Tidak terjadi heteroskdastisitas \\
$\boldsymbol{X}_{\mathbf{3}}$ & 0,978 & Tidak terjadi heteroskdastisitas \\
$\boldsymbol{X}_{\mathbf{4}}$ & 0,969 & Tidak terjadi heteroskdastisitas \\
\hline
\end{tabular}

Sumber : Hasil Olah Data, 2020

Berdasarkan hasil analisis di atas, dapat diketahui bahwa nilai korelasi 4 variabel independen dengan Unstandardized Residual memiliki nilai sig >0,05. Karena signifikansi lebih dari 0,05 maka dapat disimpulkan bahwa tidak terjadi masalah heteroskedastisitas pada model regresi yang diajukan.

4. Hasil Analisis Regresi Berganda

Setelah diadakan uji asumsi klasik berupa uji multikolinearitas, uji autokorelasi dan uji heterokedtisitas terhadap variabel-variabel penelitian, maka dapat diasumsikan bahwa data pada variabel penelitian telah memenuhi syarat untuk diadakan analisis regresi linear, berdasarkan diagram jalur yang telah dirancang di desain penelitian.

Tabel 5. Hasil Analisis Regresi Linier Berganda

\begin{tabular}{ll|lll}
\hline \multicolumn{1}{c}{ Model } & Koefisien & Std.Error & Prob Sig \\
\hline Constant & 10,577 & 0,670 &, 000 \\
CAR $\left(\boldsymbol{X}_{\mathbf{1}}\right)$ & $-0,017$ & 0,014 &, 267 \\
NPL $\left(\boldsymbol{X}_{\mathbf{2}}\right)$ & $-0,084$ & 0,063 &, 205 \\
BOPO $\left(\boldsymbol{X}_{\mathbf{3}}\right)$ & $-0,100$ & 0,003 &, 000 \\
LDR $\left(\boldsymbol{X}_{\mathbf{4}}\right)$ & 0,000 & 0,005 &, 967 \\
\hline
\end{tabular}

Sumber : Hasil Olah Data, 2020

Berdasarkan hasil uji regresi linier berganda di atas, diperoleh persamaan regresi sebagai berikut:

$$
Y=10,577-0,017 \mathrm{X}_{1}-0,084 \mathrm{X}_{2}-0,100 \mathrm{X}_{3}+0,000 \mathrm{X}_{4}
$$

Dari persamaan tersebut dapat diketahui:

a. Nilai konstanta sebesar 10,577 menunjukkan bahwa jika CAR (X1), NPL(X2), BOPO (X3), dan LDR (X4) pada rasio keuanga bernilai 0, maka tingkat ROA (Y) pada kinerja keuangan sebesar 10,577

b. Nilai koefisien regresi CAR terhadap ROA ( $\left(\mathrm{yx}_{1}\right)$ adalah sebesar $-0,017$ dengan nilai negatif. Hal ini berarti bahwa bahwa setiap peningkatan 1 satuan CAR , 
maka ROA akan menurun sebesar 0,017 dengan asumsi bahwa variabel lain yang mempengaruhi konstan.

c. Nilai koefisien regresi NPL terhadap ROA $\left(\rho \mathrm{yx}_{2}\right)$ adalah sebesar $-0,084$ dengan nilai negatif. Hal ini berarti bahwa bahwa setiap peningkatan 1 satuan NPL , maka ROA akan menurun sebesar 0,084 dengan asumsi bahwa variabel lain yang mempengaruhi konstan.

d. Nilai koefisien regresi BOPO terhadap ROA ( $\left.\rho \mathrm{yx}_{3}\right)$ adalah sebesar $-0,100$ dengan nilai negatif. Hal ini berarti bahwa bahwa setiap peningkatan 1 satuan NPL , maka ROA akan menurun sebesar 0,100 dengan asumsi bahwa variabel lain yang mempengaruhi konstan.

e. Nilai koefisien regresi LDR terhadap ROA $\left(\rho \mathrm{yx}_{4}\right)$ adalah sebesar 0,000 . Hal ini berarti bahwa bahwa peningkatan ataupun menurunnya nilai LDR tidak memberikan perubahan nilai pada ROA apabila diasumsikan bahwa variabel lain yang mempengaruhi konstan.

5. Hasil Uji t (Uji Hipotesis Parsial)

Selanjutnya, secara parsial akan diuji masing-masing variabel pada rasio keuangan yaitu CAR (X1), NPL(X2), BOPO (X3), dan LDR (X4) apakah berpengaruh terhadap variael kinerja keuangan yaitu ROA $(Y)$. Digunakan Uji Statistik $t$, untuk mengetahui perngaruh variabel-variabel bebas terhadap variabel terikat secara parsial. Dengan menggunakan SPSS, maka diperoleh hasil Uji t variabel independen $\mathrm{X}_{1}, \mathrm{X}_{2}, \mathrm{X}_{3}$, dan $\mathrm{X}_{4}$ terhadap variabel dependen $Y$ dengan nilai $t_{\text {tabel }}=2,119$ pada taraf signifikansi 0,05 dengan $d F=16$ berdasarkan nilai uji dua sisi.

Tabel 6. Hasil Uji t terhadap Variabel Kinerja Keuangan

\begin{tabular}{llcr}
\hline $\begin{array}{l}\text { Variabel } \\
\text { Independen }\end{array}$ & $\mathbf{t}_{\text {hitung }}: \mathbf{t}_{\text {tabel }}$ & Prob Sig \\
\hline CAR $\left(\boldsymbol{X}_{\mathbf{1}}\right)$ & $-1,149$ & 2,119 & 0,267 \\
NPL $\left(\boldsymbol{X}_{\mathbf{2}}\right)$ & $-1,322$ & 2,119 & 0,205 \\
BOPO $\left(\boldsymbol{X}_{\mathbf{3}}\right)$ & $-32,390$ & 2,119 & 0,000 \\
LDR $\left(\boldsymbol{X}_{\mathbf{4}}\right)$ & 0,042 & 2,119 & 0,967 \\
\hline
\end{tabular}

Sumber : Hasil Olah Data, 2020

Berdasarkan hasil Uji Statistik t kemudian dilakukan Uji Hipotsesis untuk mengetahui ada tidaknya pengaruh rasio keuangan terhadap kinerja keuangan secara parsial. Kriteria penarikan kesimpulan berdasarkan nilai $t$ untuk uji hipotesis parsial ini adalah:

Tolak $H_{0}$ jika $t_{\text {hitung }}>t_{\text {tabel }}$ atau $t_{\text {hitung }}<-t_{\text {tabel }}$ (signifikan)

Terima $H_{0}$ jika $-t_{\text {tabel }}<t_{\text {hitung }}<t_{\text {tabel }}$, (tidak signifikan)

Atau juga dengan berdasarkan nilai probabilitas yaitu jika nilai signfikansi ( $P$ value) $\leq \alpha=0,05$ maka $H_{0}$ ditolak. Jika sebaliknya, maka $H_{0}$ diterima.

a. Uji Hipotesis Variabel CAR $\left(\mathbf{X}_{1}\right)$ terhadap ROA(Y)

Hipotesis parsial pertama adalah hipotesis untuk menguji pengaruh CAR $\left(X_{1}\right)$ terhadap $\operatorname{ROA}(Y)$, dengan $H_{01}$ adalah hipotesis awal, dan $H_{a 1}$ adalah Hipoteseis alternatf sebagai berikut:

$H_{01}: \rho y x_{1}=0$, artinya tidak terdapat pengaruh CAR $\left(X_{1}\right)$ terhadap $\operatorname{ROA}(Y)$

$H_{11}$ : $\rho y x_{1} \neq 0$, artinya terdapat pengaruh CAR $\left(X_{1}\right)$ terhadap $\operatorname{ROA}(Y)$

Berdasarkan tabel Hasil uji t untuk Hipotesis pertama terhadap variabel kinerja keuangan yaitu ROA $(Y)$ diperoleh nilai $t_{\text {hitung }}$ untuk variabel CAR $\left(X_{1}\right)$ adalah $t_{\text {hitung }}=-1,149$ lebih besar dari $-t_{\text {tabel }}=-2,119$. Nilai $t_{\text {hitung }}$ berada pada 
daerah penerimaaan $H_{0}$. Sementara, berdasarkan nilai P-value diperoleh Sig $=$ 0,267 lebih besar dari $\alpha=0,05$. Sehingga dapat disimpulkan bahwa $H_{01}$ diterima. Dengan kata lain CAR $\left(X_{1}\right)$ tidak berpengaruh signifikan terhadap $\operatorname{ROA}(Y)$.

b. Uji Hipotesis Variabel NPL $\left(X_{2}\right)$ terhadap ROA(Y)

Hipotesis parsial kedua adalah hipotesis untuk menguji pengaruh NPL $\left(X_{2}\right)$ terhadap $\operatorname{ROA}(Y)$, dengan $H_{0}$ adalah hipotesis awal, dan $H_{1}$ adalah Hipoteseis alternatf sebagai berikut:

$H_{02}: \rho y x_{2}=0$, artinya tidak terdapat pengaruh NPL $\left(X_{2}\right)$ terhadap $\operatorname{ROA}(Y)$

$H_{12}: \rho y x_{2} \neq 0$, artinya terdapat pengaruh NPL $\left(X_{2}\right)$ terhadap ROA $(Y)$

Berdasarkan tabel Hasil uji t untuk Hipotesis kedua terhadap variabel kinerja keuangan yaitu ROA $(Y)$ diperoleh nilai $t_{\text {hitung }}$ untuk variabel NPL $\left(X_{2}\right)$ adalah $t_{\text {hitung }}=-1,322$ lebih besar dari $-t_{\text {tabel }}=-2,119$. Nilai $t_{\text {hitung }}$ berada pada daerah penerimaan $H_{0}$. Sementara, berdasarkan nilai P-value diperoleh Sig = 0,967 lebih besar dari $\alpha=0,05$. Sehingga dapat disimpulkan bahwa $H_{02}$ diterima, dan $H_{12}$ ditolak. Dengan kata lain NPL $\left(X_{2}\right)$ tidak memiliki pengaruh yang signifikan terhadap ROA $(Y)$

c. Uji Hipotesis Variabel BOPO $\left(X_{3}\right)$ terhadap ROA(Y)

Hipotesis parsial ketiga adalah hipotesis untuk menguji pengaruh BOPO $\left(X_{3}\right)$ terhadap $\operatorname{ROA}(Y)$, dengan $H_{03}$ adalah hipotesis awal, dan $H_{13}$ adalah Hipoteseis alternatf sebagai berikut:

$H_{03}: \rho y x_{3}=0$, artinya tidak terdapat pengaruh BOPO $\left(X_{3}\right)$ terhadap $\operatorname{ROA}(Y)$

$H_{13}$ : $\rho y x_{3} \neq 0$, artinya terdapat pengaruh BOPO $\left(X_{3}\right)$ terhadap ROA $(Y)$

Berdasarkan tabel Hasil uji t untuk Hipotesis kedua terhadap variabel kinerja keuangan yaitu ROA $(Y)$ diperoleh nilai $t_{\text {hitung }}$ untuk variabel BOPO $\left(X_{3}\right)$ adalah adalah $t_{\text {hitung }}=-32,390$ lebih kecil dari $-t_{\text {tabel }}=-2,119$. Nilai $t_{\text {hitung }}$ berada pada daerah penolakan $H_{0}$. Sementara, berdasarkan nilai Pvalue diperoleh $\mathrm{Sig}=0,000$ lebih kecil dari $\alpha=0,05$. Sehingga dapat disimpulkan bahwa $H_{03}$ ditolak. Dengan kata lain BOPO $\left(X_{3}\right)$ memiliki pengaruh yang signifikan terhadap $\operatorname{ROA}(Y)$.

d. Uji Hipotesis Variabel LDR $\left(X_{4}\right)$ terhadap ROA(Y)

Hipotesis parsial ketiga adalah hipotesis untuk menguji pengaruh LDR $\left(X_{4}\right)$ terhadap $\operatorname{ROA}(Y)$, dengan $H_{04}$ adalah hipotesis awal, dan $H_{14}$ adalah Hipoteseis alternatf sebagai berikut:

$H_{04}: \rho y x_{4}=0$, artinya tidak terdapat pengaruh $\operatorname{LDR}\left(X_{4}\right)$ terhadap $\operatorname{ROA}(Y)$

$H_{14}: \rho y x_{4} \neq 0$, artinya terdapat pengaruh $\operatorname{LDR}\left(X_{4}\right)$ terhadap $\operatorname{ROA}(Y)$

Berdasarkan tabel Hasil uji t untuk Hipotesis keempat terhadap variabel kinerja keuangan yaitu ROA $(Y)$ diperoleh nilai $t_{\text {hitung }}$ untuk variabel LDR $\left(X_{4}\right)$ adalah $t_{\text {hitung }}=0,042$ lebih kecil dari $t_{\text {tabel }}=2,119$. Nilai $t_{\text {hitung }}$ berada pada daerah penerimaan $H_{04}$. Sementara, berdasarkan nilai P-value diperoleh $\operatorname{Sig}=0,967$ lebih besar dari $\alpha=0,05$. Sehingga dapat disimpulkan bahwa $H_{04}$ diterima. Dengan kata lain LDR $\left(X_{4}\right)$ tidak memiliki pengaruh yang signifikan terhadap $\operatorname{ROA}(Y)$.

Tabel 7. Hasil Uji Hipotesis Parsial 


\begin{tabular}{lll}
\hline Hipotesis Uji & Hasil Uji & Kriteria \\
\hline $\boldsymbol{H}_{\mathbf{0 1}}: \boldsymbol{\rho} \boldsymbol{y} \boldsymbol{x}_{\mathbf{1}}=\mathbf{0}$ vs $\boldsymbol{H}_{\mathbf{1 1}}: \boldsymbol{\rho} \boldsymbol{y} \boldsymbol{x}_{\mathbf{1}} \neq \mathbf{0}$ & Terimaa $H_{01}$ & $\begin{array}{l}\text { Tidak berpengaruh } \\
\text { signifikan }\end{array}$ \\
$\boldsymbol{H}_{\mathbf{0 2}}: \boldsymbol{\rho} \boldsymbol{y} \boldsymbol{x}_{\mathbf{2}}=\mathbf{0}$ vs $\boldsymbol{H}_{\mathbf{1 2}}: \boldsymbol{\rho} \boldsymbol{y} \boldsymbol{x}_{\mathbf{2}} \neq \mathbf{0}$ & Terimaa $H_{02}$ & $\begin{array}{l}\text { Tidak berpengaruh } \\
\text { signifikan }\end{array}$ \\
$\boldsymbol{H}_{\mathbf{0 3}}: \boldsymbol{\rho} \boldsymbol{y} \boldsymbol{x}_{\mathbf{3}}=\mathbf{0}$ vs $\boldsymbol{H}_{\mathbf{1 3}}: \boldsymbol{\rho} \boldsymbol{y} \boldsymbol{x}_{\mathbf{3}} \neq \mathbf{0}$ & Tolak $H_{03}$ & $\begin{array}{l}\text { Berpengaruh } \\
\text { signifikan }\end{array}$ \\
$\boldsymbol{H}_{\mathbf{0 4}}: \boldsymbol{\rho} \boldsymbol{y} \boldsymbol{x}_{\mathbf{4}}=\mathbf{0}$ vs $\boldsymbol{H}_{\mathbf{1 4}}: \boldsymbol{\rho} \boldsymbol{y} \boldsymbol{x}_{\mathbf{4}} \neq \mathbf{0}$ & Terima $H_{04}$ & $\begin{array}{l}\text { Tidak berpengaruh } \\
\text { signifikan }\end{array}$ \\
\hline
\end{tabular}

Sumber : Hasil Olah Data, 2020

6. Hasil Uji F ( Uji Hipotesis Simultan)

Pengujian ini untuk mengetahui hasil uji hipotesis pengaruh secara simultan Rasio Keuangan terhadap Kinerja Keuangan. Uji F two way Anova dilakukan dengan SPSS, sehingga diperoleh hasil berikut dengan signifikansi $\alpha=0,05$.

Tabel 8. Hasil Uji Anova 2 arah terhadap Variabel Dependen

\begin{tabular}{lllcl}
\hline \multicolumn{1}{c}{ Model } & df & $\mathbf{F}$ & $\boldsymbol{R}^{\mathbf{2}}$ & Prob Sig \\
\hline Regresi & 4 & 523,695 & 0,991 & 0,000 \\
Residual & 16 & & & \\
Total & 20 & & & \\
\hline
\end{tabular}

Sumber: Hasil Olah Data, 2020

$H_{0}: \rho y x=0$, artinya tidak terdapat pengaruh secara bersama-sama variabel Rasio Keuangan CAR $\left(X_{1}\right)$, NPL $\left(X_{2}\right)$, BOPO $\left(X_{3}\right)$, LDR $\left(X_{4}\right)$ terhadap Kinerja Keuangan ROA $(Y)$

$H_{1}: \rho y x \neq 0$, artinya terdapat pengaruh secara bersama-sama variabel Rasio Keuangan CAR $\left(X_{1}\right)$, NPL $\left(X_{2}\right)$, BOPO $\left(X_{3}\right)$, LDR $\left(X_{4}\right)$ terhadap Kinerja Keuangan ROA $(Y)$

Dengan kriteria penarikan kesimpulan sebagai berikut:

Jika $F_{\text {hitung }} \geq F_{\text {tabel }}$, maka $H_{0}$ ditolak, $H_{1}$ diterima (signifikan)

Jika $F_{\text {hitung }} \leq F_{\text {tabel }}$, maka $H_{0}$ diterima, $H_{1}$ ditolak (tidak signifikan)

diperoleh distribusi nilai $\mathrm{F}$ tabel dengan df pembilang $\mathrm{k}$ (banyaknya variabel independen) dan df penyebut $(\mathrm{n}-\mathrm{k}-1)$. Diperoleh nila $F_{\text {tabel }}(4 ; 16)=4,77$ dan $F_{\text {hitung }}=523,695$. Selanjutnya berdasarkan nilai signifikansi dapat diketahui nilai Sig $=0,000<0,05$. Oleh karena $F_{\text {hitung }}>F_{\text {tabel }}$, dan nilai Sig $<0,05$ maka $H_{0}$ ditolak dan $H_{1}$ diterima yang berarti variabel-variabel pada rasio keuangan secara simultan berpengaruh secara signifikan terhadap Kinerja Keuangan.

7. Hasil Analisis Pengaruh tiap Variabel Independen

Selanjutmya, berdasarkan nilai koefisien determinasi $\left(R^{2}\right)=0,991$, maka dapat dikatakan bahwa variabel-variabel pada Rasio Keuangan secara simultan berpengaruh sebesar $99 \%$ terhadap terjadinya perubahan pada variabel Kinerja Keuangan. Yang berarti hanya sekitar $1 \%$ kinerja keuangan dipengaruhi oleh variabel lain yang tidak diteliti.

Dari sini dapat diketahui bahwa variabel-variabel independen pada rasio keuangan memberikan hampir semua informasi yang dibutuhkan untuk memprediksi variabel kinerja keuangan.

Nilai koefisien determinasi $\left(R^{2}\right)=0,991$ juga menunjukkan total sumbangan efektif variabel rasio keuangan terhadap kinerja keuangan. Untuk mengetahui sumbangan 
efektif tiap aspek pada rasio keuangan terhadap kinerja keuangan maka digunakan rumus sebagai berikut:

$$
S E_{X_{i}}=\left|\frac{b_{X_{i}} \cdot C P \cdot R^{2}}{\text { Regression }}\right| \times 100 \%
$$

Dengan

$b_{X_{i}}=$ koefisien $b$ komponen $X_{i}$

$C P=$ cross product komponen $X_{i}$

Regression $=$ nilai regresi

$R^{2}=$ sumbangan efektif total

Dari output SPSS kemudian diperoleh beberapa hasil yang kemudian dirangkum sebagai berikut:

Tabel 9. Nilai Pengaruh Variabel Rasio Keuangan

\begin{tabular}{ccccc}
\hline $\begin{array}{c}\text { Variabel Rasio } \\
\text { Keuangan }\end{array}$ & b & \multicolumn{1}{c}{ CP } & Regresi & $\boldsymbol{R}^{\mathbf{2}}$ \\
\hline $\boldsymbol{C A R}\left(\boldsymbol{X}_{\mathbf{1}}\right)$ & $-0,0166$ & 231,084 & & \\
$\boldsymbol{N} \boldsymbol{P L}\left(\boldsymbol{X}_{\mathbf{2}}\right)$ & $-0,0835$ & $-30,762$ & 150,7862 & $99,1 \%$ \\
$\boldsymbol{B} \boldsymbol{P P O}\left(\boldsymbol{X}_{\mathbf{3}}\right)$ & $-0,0997$ & $-1524,607$ & & \\
$\boldsymbol{L D D R}\left(\boldsymbol{X}_{\mathbf{4}}\right)$ & 0,0002 & $-41,41$ & & \\
\hline
\end{tabular}

Sumber : Hasil Olah Data, 2020

Sehingga diperoleh persentase pengaruh tiap variabel adalah:

$$
\begin{aligned}
S E_{C A R}= & \left|\frac{-0,0166.231,084.0,991}{150,7682}\right| \times 100 \%=3 \% \\
S E_{N P L}= & \left|\frac{-0,0835 \cdot-30,762.0,991}{150,7682}\right| \times 100 \%=2 \% \\
S E_{B O P O}= & \left|\frac{-0,0997 \cdot-1524,607.0,991}{150,7682}\right| \times 100 \%=93 \% \\
& S E_{L D R}=\left|\frac{-0,0002 \cdot-41,410.0,991}{150,7682}\right| \times 100 \%=1 \%
\end{aligned}
$$

Berdasarkan hasil perhitungan SE di atas dapat disimpulkan bahwa dari ke empat variabel rasio keuangan, variabel BOPO yang memberikan pengaruh yang paling besar terhadap kinerja keuangan yaitu sekitar $93 \%$ dari total pengaruh efektif variabel rasio keuangan terhadap kinerja keuangan. 


\section{E. KESIMPULAN}

Berdasarkan hasil penelitian yang telah dilakukan, dapat disimpulkan bahwa rasio CAR $\left(X_{1}\right)$, NPL $\left(X_{2}\right)$, LDR $\left(X_{4}\right)$ secara parsial tidak berpengaruh signifikan terhadap $\operatorname{ROA}(Y)$, sedangkan untuk rasio BOPO $\left(X_{3}\right)$ memiliki pengaruh yang signifikan terhadap ROA $(Y)$.

Seluruh variabel bebas yang terdiri dari CAR (Capital Adequacy Ratio), NPL (Non Performing Loan), BOPO (Biaya Operasional/ Pendapatan Operasional), dan LDR (Loan to Deposit Ratio) secara simultan berpengaruh signifikan terhadap variabel terikat yaitu Return On Assets (ROA) perusahaan perbankan yang terdaftar di Bursa Efek Indonesia.

Untuk rasio BOPO (Biaya Operasional/ Pendapatan Operasional) dari aspek pendapatan, lebih dominan pengaruhnya terhadap Return On Assets (ROA) jika dibandingkan dengan rasio CAR (Capital Adequacy Ratio) dari aspek permodalan, Rasio NPL (Non Performing Loan) dari aspek harta, Rasio LDR (Loan to Deposit Ratio) untuk aspek likuiditas.

\section{DAFTAR PUSTAKA}

Alexandri, M. B. (2008). Manajemen Keuangan Bisnis. Bandung: Alfabeta.

Darmawi, H. (2011). Manajemen Perbankan. Jakarta: Bumi Aksara.

Fahmi, I. (2012). Analisa Kinerja Keuangan , Panduan bagi Akademisi , Manajer, dan investor untuk menilai dan menganalisis bisnis dari aspek keuangan. Jakarta: Alfabeta.

Harahap, S. S. (2011). Analisis Kritis Atas Laporan Keuangan. Jakarta: Raja Grafindo Persada.

Harmono. (2011). Manajemen Keuangan Berbasis Balanced Scorecard : Pendekatan Teori, Kasus, dan Riset Bisnis (1, ed.). Jakarta: PT Bumi Aksara.

Hery. (2015). Analisis Laporan Keuangan Pendekatan Rasio Keuangan. Yogyakarta: Center for Academic Publishing Service.

Kadim, A., Sunardi, N., \& Husain, T. (2020). The modeling firm's value based on financial ratios, intellectual capital and dividend policy. Accounting, 6(5), 859-870.

Kadim, A., \& Sunardi, N. (2019). Pengaruh Profitabilitas, Ukuran Perusahaan Terhadap Leverage Implikasi Terhadap Nilai Perusahaan Cosmetics and Household yang terdaftar di Bursa Efek Indonesia. Jurnal SEKURITAS (Saham, Ekonomi, Keuangan dan Investasi), 3(1), 22-32.

Karunia, C. (2013). Analisis Pengaruh Rasio Capital, Asset Quality dan Liquidity Terhadap Kinerja Keuangan Pada Sektor Perbankan Yang Terdaftar Di Bursa Efek Indonesia (BEI) Periode 2007-2011. Jurnal IImiah Mahasiswa Universitas Surabaya, 2(1), 1-17.

Kasmir. (2011). BANK DAN LEMBAGA KEUANGAN LAINNYA. Jakarta: Raja Grafindo Persada.

Kasmir. (2012). Analisis Laporan Keuangan. Jakarta: Raja Grafindo Persada.

Lely. (2007). Evaluasi Pengaruh CAMEL Terhadap Kinerja Perusahaan. Buletin Studi Ekonomi, 12(1). 
Pandia, F. (2012). Manajemen Dana dan Kesehatan Bank (1st ed.). Jakarta: Rineka Cipta.

Rindjin, K. (2008). Pengantar Perbankan Dan Lembaga Keuangan Bukan Bank (2nd ed.). Jakarta: Gramedia Pustaka Utama.

Rindjin, K. (2012). Pengantar Perbankan dan Keuangan Bukan Bank. Jakarta: Gramedia Pustaka Utama.

Rudianto, E. (2013). Akuntansi Manajemen Informasi untuk Pengambilan Keputusan strategis. Jakarta: Erlangga.

Setiawan, L. (2015). Pengaruh Rasio Camel Terhadap Kinerja Keuangan Perbankan Yang Diukur Dengan Return On Assets (Studi Kasus Pada Perusahaan Perbankan Yang Terdaftar Di BEI Tahun 2009-2013). Journal Of Accounting, 1(1), 1-28.

Sutrisno. (2012). Manajemen Keuangan Teori, Konsep dan Aplikasi (8th ed.). Yogyakarta: Ekonosia.

Sunardi, N. (2017). Pengaruh Profitabilitas, Firm Size, Risiko Bisnis, Asset Growth, Leverage, Kebijakan Dividen Terhadap Institutional Ownership (Perusahaan Property \& Real Estate yang terdaftar di Bursa Efek Indonesia Tahun 2011-2014). INOVASI, 2(2).

Sunardi, N. (2020). Kesehatan Bank Umum Syariah yang terdaftar di Otoritas Jasa Keuangan dengan metode Risk Based Bank Rating (RBBR). Jurnal SEKURITAS (Saham, Ekonomi, Keuangan dan Investasi), 3(2), 132-147.

Sunardi, N., \& Febrianti, F. (2020). Likuiditas dan Kebijakan Hutang Pengaruhnya terhadap Kinerja Perusahaan dan Dampaknya Terhadap Nilai Perusahaan pada Industri Sektor Telekomunikasi di Indonesia. JIMF (Jurnal IImiah Manajemen Forkamma), 3(3).

Veithzal, R. dkk. (2013). Credit management handbook manajemen perkreditan cara mudah menganalisis kredit. Jakarta: Rajawali Pers. 